\title{
A INFLUÊNCIA DA URBANIZAÇÃo NA AMPLITUDE TÉRMICA DA CIDADE DE BELO HORIZONTE
}

\author{
Renata Alves Siqueira ${ }^{1}$
}

\begin{abstract}
Resumo
O objetivo desse trabalho é analisar a relação existente entre a amplitude térmica e o adensamento urbano, considerando como fatores de adensamento urbano a densidade demográfica e a cobertura vegetal do solo. Para tanto foram utilizados dados do Instituto Brasileiro de Geografia e Estatísticas (IBGE), e dos trabalhos de (Fonseca, Lobo, Garcia, \& Assis, 2013)e (ASSIS, 2010).
\end{abstract}

Palavras Chave:uso do solo, Cobertura vegetal, temperatura, crescimento urbano.

\begin{abstract}
The aim of thisstudyistoanalyzetherelationshipbetweenthetemperature range and theurbandensity ,consideringhowurbandensityfactorstopopulationdensity and vegetation cover theground. Therefore, weused data fromtheBrazilianInstitute of Geography and Statistics (IBGE), and work (Fonseca, Wolf, Garcia, \&Assisi, 2013) and (ASSIS, 2010).
\end{abstract}

1 Universidade Federal de Minas Gerais - UFMG, Instituto de Geociências-IGC, (Doutorado). siq.renata@gmail.com 


\section{1- INTRODUÇÃO}

A urbanização influencia diretamente o clima da cidade. Fatores como ocupação do solo, emissões atmosféricas, adensamento populacional e supressão vegetal são fundamentais na determinação da condição climática de um local, provocando direta ou indiretamente, alterações na atmosfera urbana. Estudos sobre as alterações climáticas influenciadas pela urbanização não são novidade. Os primeiros estudos conhecidos datam do século XIX, na França e Inglaterra. No Brasil esses trabalhos começam a ser desenvolvidos na década de 70, e já indicavam a formação de ilhas e calor nos centros urbanos.

Segundo (OKE, 1978)apud (ROSSI \& KRUGER)o clima urbano é o resultadodas modificações causadas pelo processo de urbanização na superfície terrestre e nas características atmosféricas de um determinado local. O chamado clima urbano caracteriza-se principalmente pelos chamados microclimas ou ilhas de calor, uma vez que as áreas urbanas são constituídas por materiais de características diversas, repercutindo diretamente no conforto térmico das pessoas que habitam o local.

Dentre as modificações decorrentes da urbanização estão a crescente substituição da vegetação, além das próprias edificações, construídas com materiais condutores de energia térmica, que exercem grande influencia na composição do clima. Essas modificações alteram os fluxos de ventilação e energia solar, que acabam por alterar a temperatura da superfície do ar. Áreas pouco arborizadas, com alto índice de impermeabilização do solo e com grande densidade de construções tendem a ser mais quentes.

A arborização é um parâmetro de conforto e qualidade de vida muito importante para o meio urbano, uma vez que são promotoras de sombreamento, conforto térmico e umidade do ar. Alguns estudos mostram que a redução das áreas verdes ${ }^{2}$ e a modificação da superfície do solo, decorrente da ocupação urbana, geram diferenças significativas de temperatura entre a cidade e o campo. Sob esse aspecto, áreas pouco arborizadas com maior densidade de construções possuem grande potencial para alterações no clima urbano. A Organização das Nações Unidas para a Educação, a Ciência e a Cultura (UNESCO) recomenda um índice de área verde dede $12,0 \mathrm{~m} 2 /$ hab, outros estudos sugerem $15 \mathrm{~m} 2 / \mathrm{hab}^{3}$, mas não há consenso com relação aos índices

\footnotetext{
2 Para esse estudo, são consideradas áreas verdes espaços livres onde o elemento dominante é a vegetação, sem nenhum tipo de pavimentação.

3 Fonte: Com quanta árvores se faz uma cidade
} 
(França, 2012). Consenso, no entanto é que crescimento urbano é fator de aumento da temperatura local.

\section{2- A ÁREA DE ESTUDO}

Em função da complexidade, e da fonte de dados disponíveis, utiliza-se, como área de estudo, o limite administrativo do município de Belo horizonte.

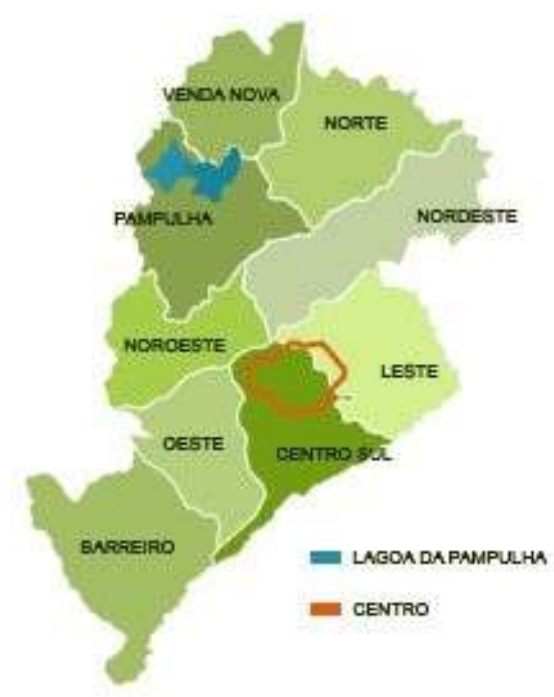

Figura 1 - Mapa de Belo Horizonte. Fonte: http://www.webcir.org/noticir/2008 vol5 n5/img/mapa bh.jpg

Belo Horizonte, uma cidade projetada para ser a capital de Minas Gerais, já superou, desde a década de 1940, a expectativa de crescimento prevista em seu plano original, e há muito tem sofrido os efeitos perversos da urbanização. O clima ameno tão ressaltado pela comissão construtora da nova capital4, com verões suaves e invernos brandos, já não é mais tão perceptível na cidade.

A expansão urbana verificada na segunda metade do século XIX, os limites da cidade real extrapolaram e muito o limite da cidade projetada, os limites da Avenida do Contorno. Esse crescimento, caracterizado por um processo de verticalização acelerado e posteriormente de impermeabilização ostensiva do solo, com o asfaltamento de vias que antes eram de paralelepípedo, e a canalização dos cursos d água, adensamento de edificações modificou definitivamente o padrão climático da cidade, especialmente no que se refere à temperatura e a umidade relativa do ar (ASSIS, 2010).

4 A Comissão Construtora da Nova Capital foi nomeada pelo então governador Augusto de Lima, em 1892. Era composta pelo Eng. Aarão Reis, mais quatro engenheiros e um médico. 
Localizada na região centro sul do estado de Minas gerais, inserida na faixa intertropical, com temperatura média anual de $21,1^{\circ} \mathrm{C}$ e com registros extremos de $36,0^{\circ} \mathrm{C}$ a $3,1^{\circ} \mathrm{C}$. O clima e a vegetação apresentam estreita relação como relevo. O alinhamento topográfico da Serra do Curral, de orientação nordestesudoeste, influencia o comportamento diferencial dos elementos climáticos. Atitude média do sítio de Belo Horizonte é de $860 \mathrm{~m}$. Entretanto, existem locais acima de $1500 \mathrm{~m}$, extremo sul da Regional Barreiro, e outros com áreas na faixa de $670 \mathrm{~m}$ a $800 \mathrm{~m}$, os leitos fluviais dos ribeirões Arrudas e Onça - níveis de base locais. Tal caracterização topográfica tende a "amenizar" as temperaturas na medida em que se eleva na superfície, além de influenciar no campo anemométrico e implicar diferenciações topo e mesoclimáticas dentro da malha urbana. (ASSIS, 2010)

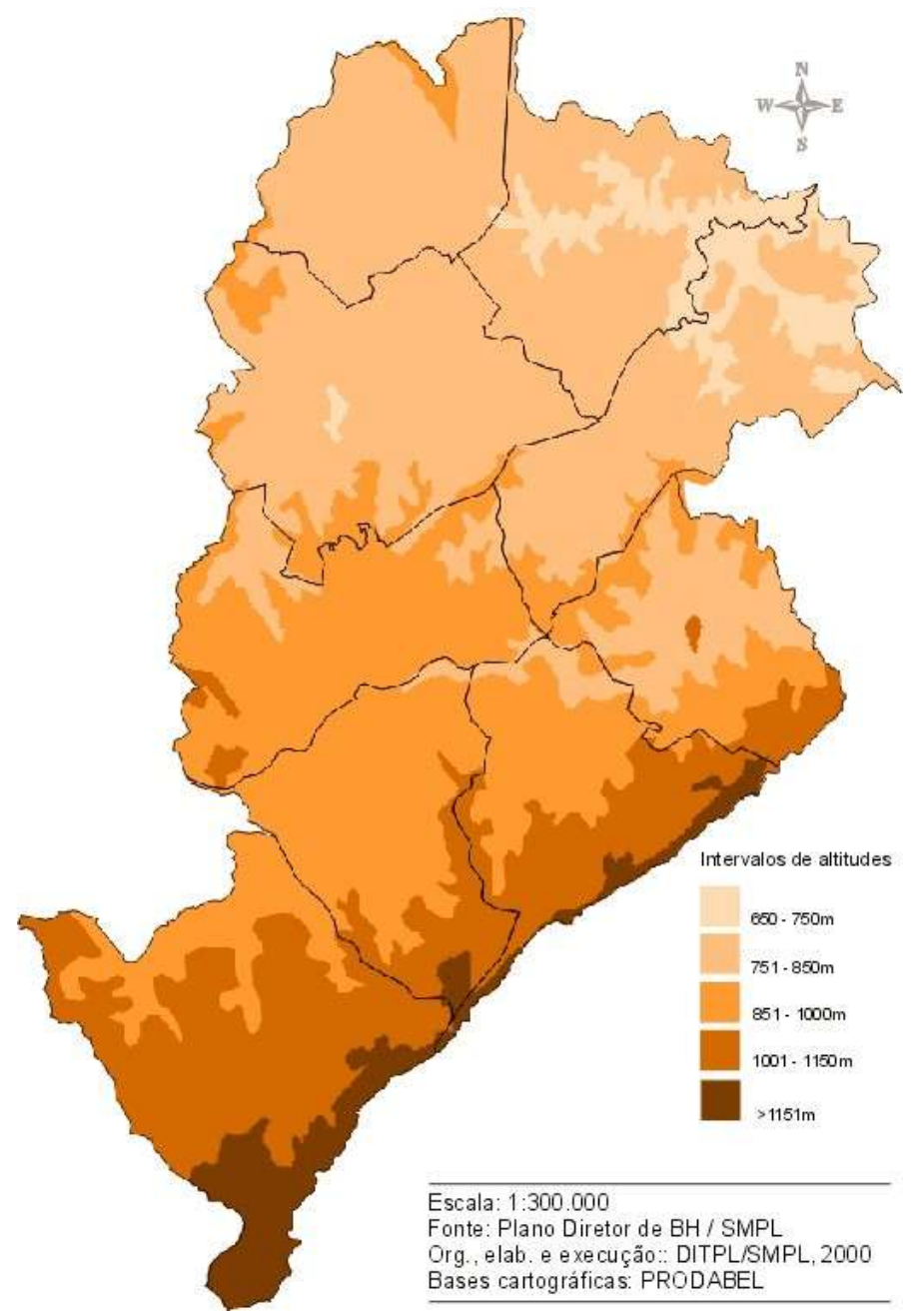

Figura 2 - Mapa do relevo de Belo Horizonte. Fonte: Plano Diretor de BH/SMPL

\section{3- MATERIAIS E MÉTODOS}

Para elaboração desse trabalho partiu-se do pressuposto de que a urbanização e a intervenção antrópica podem contribuir para aumento da temperatura. Sendo assim, optou-se 
por trabalhar com fatores que pudessem caracterizar o nível de adensamento urbano de um local. Foram escolhidos características do meio urbano, no caso densidade populacional e impermeabilização do solo, além das medições de temperatura.

Para caracterizar o adensamento urbano optou-se por trabalhar com a densidade populacional de cada setor censitário. Para tanto foi utilizado os dados de área e população residente por setor censitário, considerando a base de dados do censo IBGE de 2010.

Para caracterizar a impermeabilização do solo, foram utilizados as dados de permeabilidade de (Fonseca, Lobo, Garcia, \& Assis, 2013). Os dados de temperatura utilizados foram obtidos do trabalho de ASSIS(2010).

Para o modelo proposto, a variável dependente foi a temperatura, e as variáveis explicativas foram a densidade demográfica e a taxa de impermeabilização do solo. Foram excluídos da análise os setores censitários que não possuem população residente.

Para se avaliar as possíveis relações entre a variação da temperatura com os parâmetros de densidade demográfica e impermeabilização do solo foi adotado um modelo de análise de regressão, que permite modelar, analisar e explorar as relações espaciais e compreender melhor os fatores por trás padrões espaciais observados. Foi utilizado um modelo de regressão geograficamente ponderada (GWR), que é um modelo de regressão local, com o pressuposto de que o espaço é heterogêneo ou não-estacionário e a relação entre as variáveis dependentes e independentes assume padrões mais ou menos regionalizados. Realiza uma regressão local para cada unidade de análise levando em conta os vizinhos com base num kernel fixo ou adaptativo. (FREITAS, 2015).

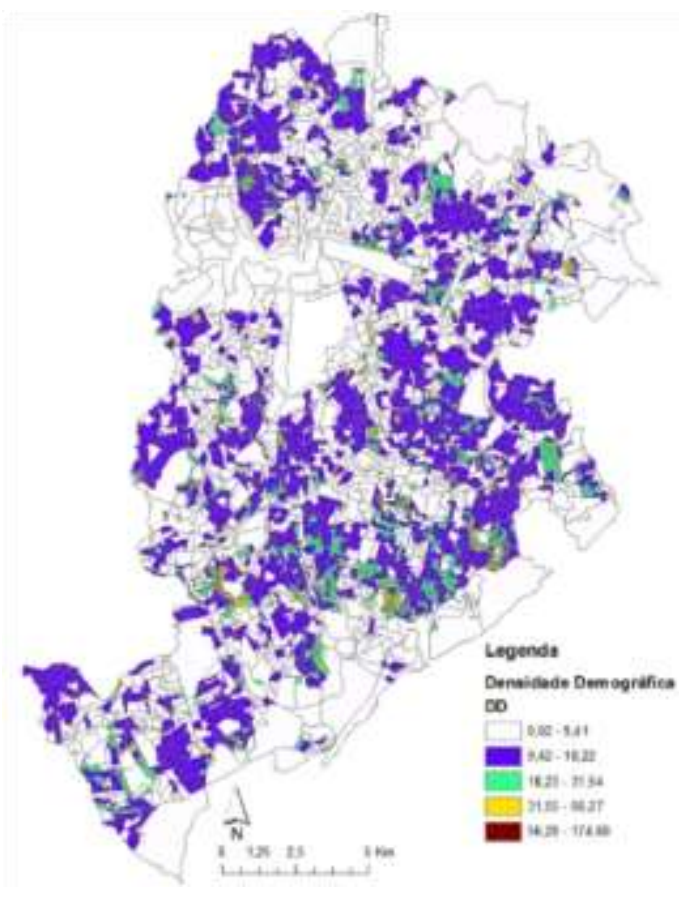


Figura 3 - Densidade populacional dos setores censitários de Belo Horizonte. Fonte: (IBGE. Instituto Brasileiro de Geografia e Estatística, 2010)

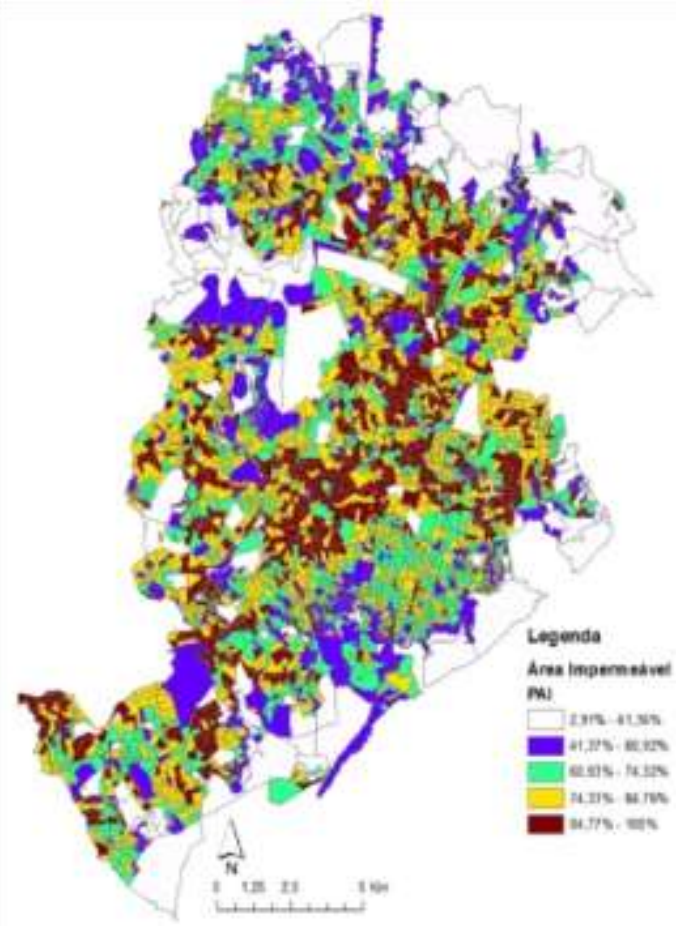

Figura 4 - Percentual de área impermeável dos setores censitários de Belo Horizonte. Fonte: (Fonseca, Lobo, Garcia, \& Assis, 2013)

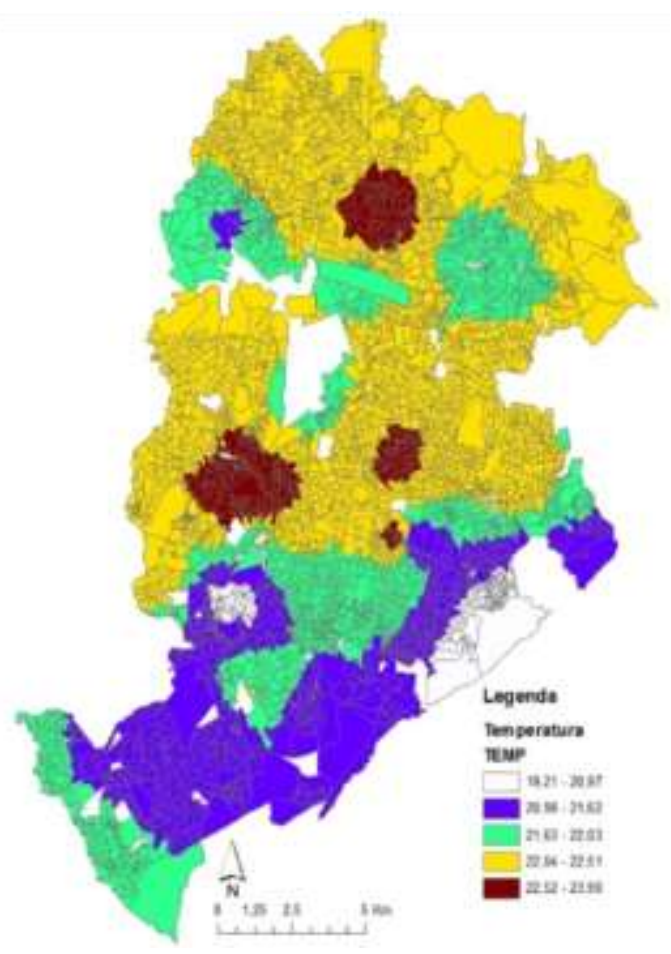

Figura 5 - Temperatura. Fonte: (ASSIS, 2010)

Cadernos do Leste 


\section{4- RESULTADOS E DISCUSSÕES}

De modo geral, conforme Figura 6, os resultados obtidos sugerem uma baixa correlação entre o percentual de áreas verdes impermeáveis, a densidade demográfica e a temperatura. Observam-se os valores do R2Local5 extremamente baixos, variando de 0 à 0,35 .

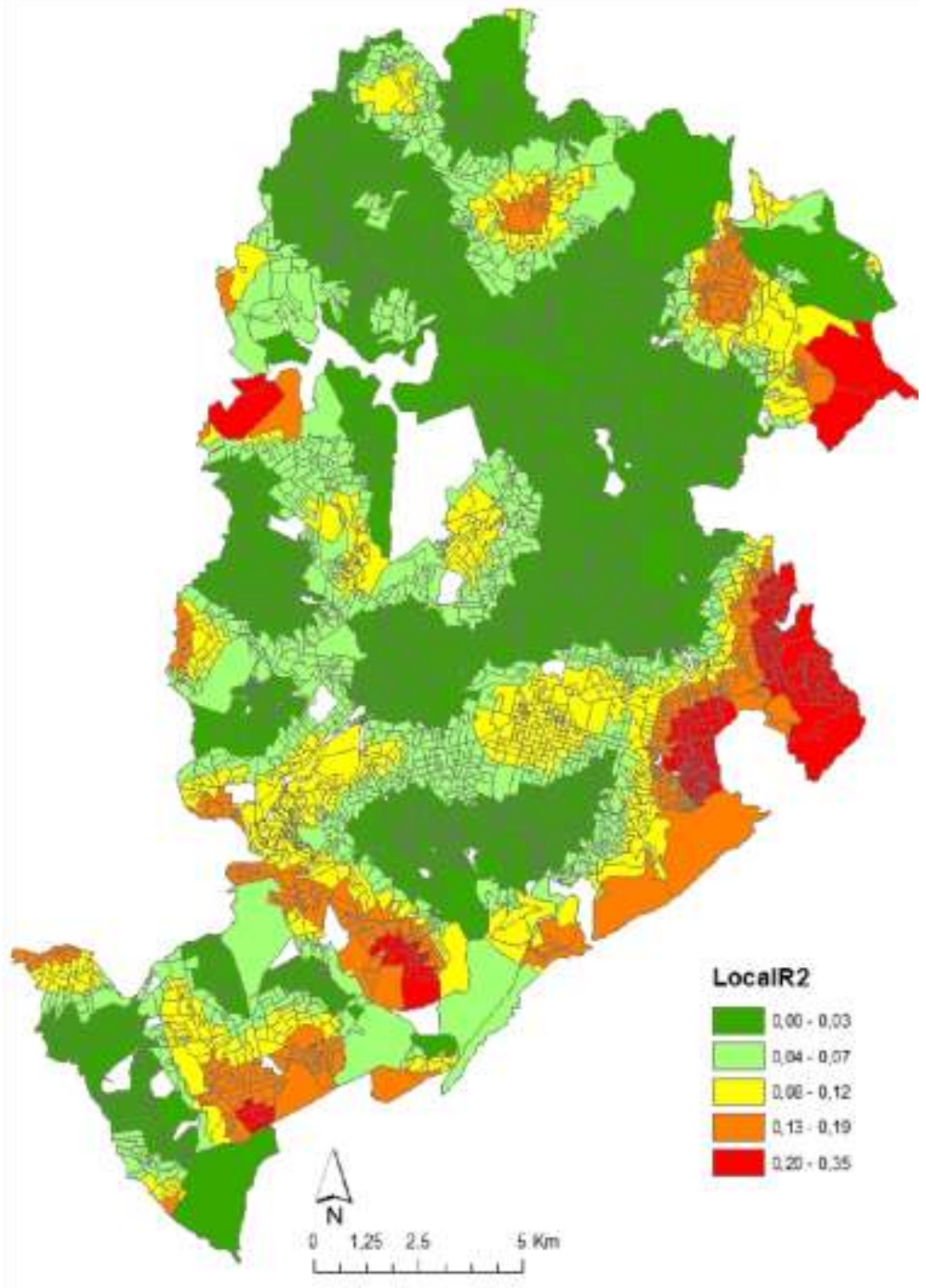

Figura 6 - Setores censitários de Belo Horizonte conforme R2Local do modelo GWR

5 Os valores de R2Local variam entre 0 e 1 . Quanto mais próximo de 0 , menor o grau de correlação da variável explicativa com relação a variável dependente, ou seja, menor o grau de dependência entre os fenômenos.

Cadernos do Leste

Artigos Cientificos

Belo Horizonte, Jan.-Dez. Vol.16, n¹6, 2016 
Observando os valores dos resíduos6 verifica-se que maior parte dos setores censitários possuem valores muito próximos de zero.

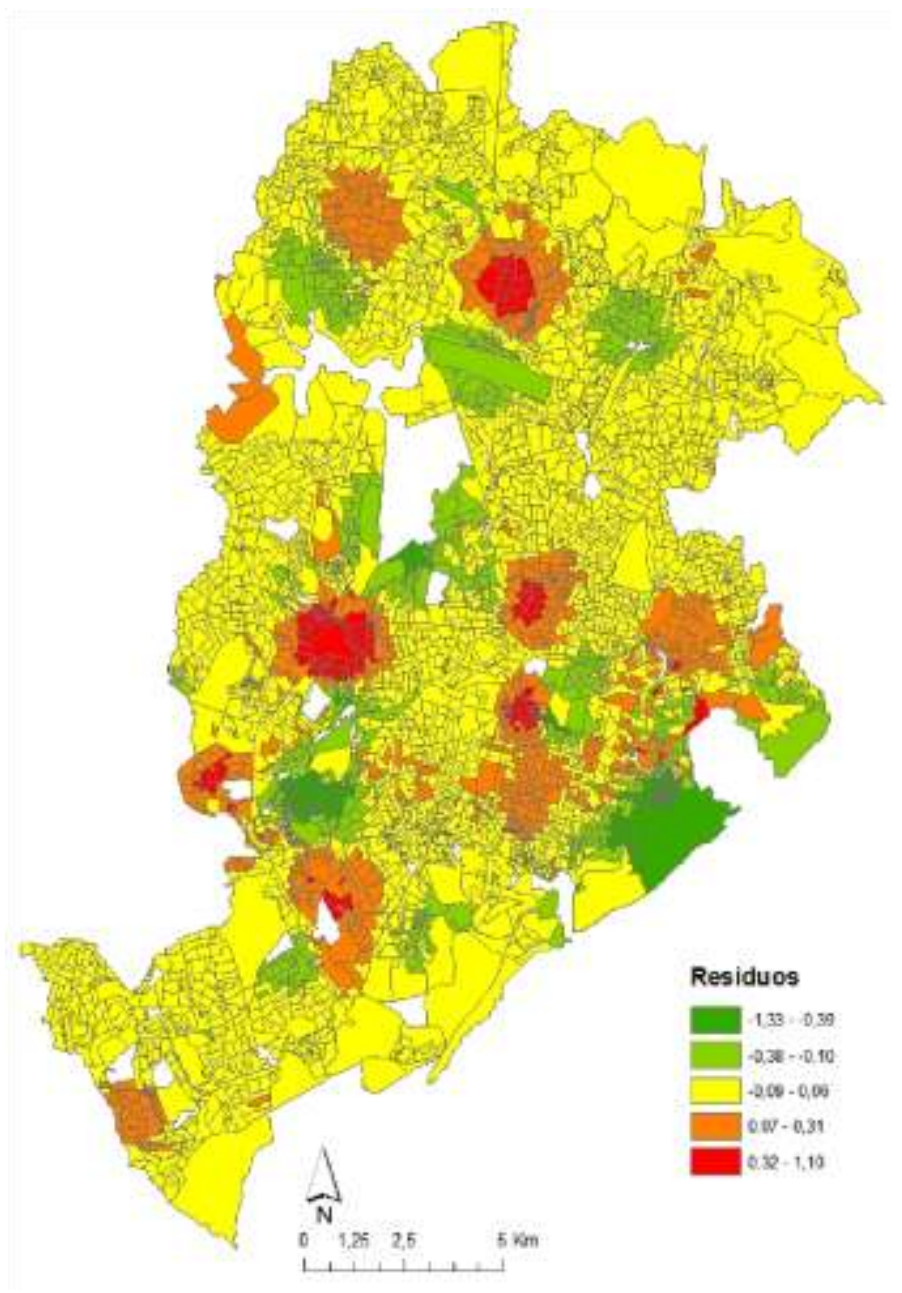

Figura 7 - Setores censitários de Belo Horizonte conforme Resíduos do modelo GWR

Analisando os parâmetros gerais do modelo, Quadro 1, observa-se valor de R2 bastante próximo de 1 (um), o que indica um bom ajuste do modelo.

6 Os resíduos indicam a porção da variável dependente que não é explicada pelo modelo. Quanto maior o valor, pior é o modelo.

Cadernos do Leste

Artigos Cientificos

Belo Horizonte, Jan.-Dez. Vol.16, n¹6, 2016 


\section{Quadro 1 - Parâmetros globais do modelo}

\begin{tabular}{|l|r|}
\hline Bandwidth & 1454,407566 \\
\hline ResidualSquares & 103,180864 \\
\hline EffectiveNumber & 187,380444 \\
\hline Sigma & 0,168188 \\
\hline AICc & 2706,947230 \\
\hline R2 & 0,881647 \\
\hline R2Adjusted & 0,8756 \\
\hline
\end{tabular}

Os valores gerais de ajuste do modelo são bons, indicando confiabilidade do modelo gerado. Os resultados apresentados nesse trabalho sugerem que não há uma relação direta entre a temperatura e a densidade demográfica e impermeabilização do solo.

Partindo-se da premissa de que áreas com maior densidade e mais impermeabilizadas possuem temperaturas mais altas e maior amplitude térmica, verifica-se que, pelos resultados do modelo, essa premissa não se confirma. Áreas com maior temperatura não correspondem, necessariamente a áreas mais adensadas ou impermeabilizadas. Considerando-se apenas as variáveis utilizadas, percebemos certa aleatoriedade nos resultados, demonstrando a baixa correlação entre elas no espaço urbano de Belo horizonte.

\section{5- CONSIDERAÇÕES FINAIS}

Os resultados apresentados reforçam a necessidade de uma análise mais detalhadados problemas ambientais urbanos, incluindo os fatores que contribuem para a formação das ilhas de calor. Pensando em toda extensão territorial da cidade de Belo Horizonte, as relações de temperatura parecem relacionar-se mais com as condições topográficas do que necessariamente de urbanização. Para que as relações entre temperatura e urbanização possam ser melhor percebidas talvez seja necessário estudar áreas menores, com densidade de dados maiores, para se chegar a conclusões mais assertivas.

\section{REFERÊNCIAS BIBLIOGRÁFICAS}

ASSIS, W. L. (2010). O sistema clima urbano do município de Belo Horizonte na perspectiva têmporo-espacial. Tese (doutorado), Universidade Federal de Minas Gerais, Instituto de Geociências, Belo Horizonte. 
BERNARDES, F. F., \& MENDES, P. (2012). A urbanização e sua influência no aumento da temperatura média no município de Uberlandia/MG. Revista Geonorte , 2, pp. 77-88. Boundarylayer climates1978LondresMethuen \&Co. LTDA

FEITOSA, S. M., GOMES, J. A., NETO, J. M., \& ANDRADE, C. S. (2011). Consequencias da Urbanização na vegetação e na temperatura da superfície de Teresina-Piaui. REVSBAU , 6, 5875.

Fonseca, D. F., Lobo, C. F., Garcia, R. A., \& Assis, W. L. (13-18 de abril de 2013). Verticalização e permeabilização do solo urbano: entre as promessas e a realidade - considerações com base no caso de Belo Borizonte. Anais XVI Simpósio brasileiro de sensoliamentoremoto .

França, E. (27 de 11 de 2012). Revista Planeta. (Terra, Editor) Acesso em 25 de 11 de 2015, disponível em www.revistaplaneta.com.br: http://www.revistaplaneta.com.br/comquantas-arvores-se-faz-uma-cidade/

FREITAS, M. W. (s.d.). Regressão geograficamente poderada (GWR): Análise de fenômenos com heterogeneidade espacial. (M. d. Tecnologia, Ed.) Acesso em 15 de novembro de 2015, disponível

em http://mundogeoconnect.com/2011/arquivos/palestras/marcos_wellausen_dias_de_freitasregre ssao_geograficamente_ponderada.pdf

IBGE. Instituto Brasileiro de Geografia e Estatística. (2010). Banco de dados do universo. Acesso em 01 de Novembro de 2015, disponível em IBGE: http://downloads.ibge.gov.br/downloads_estatisticas.htm

ROSSI, F. A., \& KRUGER, E. L. (s.d.). Análise da Influência da ocupação urbana na variação de temperatura em localidades de Curitica. Acesso em 15 de 11 de 2015, disponível em www.degraf.ufpr.br/docentes/.../2004_VISBCG_Rossi_Kruger.pdf 